Journal of

Molecular Microbiology

and Biotechnology
J Mol Microbiol Biotechnol 2008;15:8-15

DOI: $\underline{10.1159 / 000111988}$

\title{
Engineering Biocatalysts for Production of Commodity Chemicals
}

\author{
K.T. Shanmugam L.O. Ingram \\ Department of Microbiology and Cell Science, University of Florida, Gainesville, Fla., USA
}

\section{Key Words}

Biocatalysts · Lactic acid · Succinic acid • Acetic acid •

Redox $\cdot$ Bioconversion

\begin{abstract}
Lignocellulosic biomass is an attractive alternate to petroleum for production of both fuels and commodity chemicals. This conversion of biomass would require a new generation of microbial biocatalysts that can convert all the sugars present in the biomass to the desired compounds. In this review, the critical factors that need to be considered in engineering such microbial biocatalysts for cost-effective fermentation of sugars are discussed with specific emphasis on commodity chemicals such as lactic acid, succinic acid and acetic acid.

Copyright $\odot 2008$ S. Karger AG, Basel
\end{abstract}

\section{Introduction}

Petroleum serves as a feedstock for production of both fuels and commodity chemicals. Continued use of petrochemicals that elevate the atmospheric $\mathrm{CO}_{2}$ level combined with the potential for rapid depletion of this finite resource has necessitated a need to replace petroleum with renewable resources such as biomass as the feedstock [Dukes, 2003; Kheshgi et al., 2000]. Microorgan- isms have the versatility to metabolize sugars to a number of compounds at varying rates and purity. Several of these biocatalysts, as isolated from nature, ferment sugars to ethanol (Saccharomyces cerevisiae, Zymomonas mobilis), lactic acid (LA; various LA bacteria), butanol (Clostridium acetobutylicum), succinic acid (Actinobacillus succinogenes) and acetic acid (Clostridium formicoaceticum), among others [Bothast and Schlicher, 2005; Drake and Daniel, 2004; Hofvendahl and Hans-Hagerdal, 2000; Huang et al., 1998; Jones and Woods, 1986]. Some of these microbes have been successfully utilized at the industrial scale for production of the specific product, especially ethanol and LA [Bothast and Schlicher, 2005; Hofvendahl and Hans-Hagerdal, 2000]. In this review, we will attempt to highlight recent developments in biocatalyst development for the production of three commodity chemicals, LA, succinic acid and acetic acid. The metabolic pathways utilized by microbes for production of each one of these three compounds have some unique physiological characteristics and this review will focus mostly on these properties and attempts to overcome these limitations. Since there are a copious number of reviews written on microbial production of various commodity chemicals from renewable resources, this review will be limited to recent literature and the reader is referred to other reviews for completeness as well as for historical context [Datta and Henry, 2006; Hahn-Hagerdal et al., 2006; Lynd et al., 2005; Narayanan et al.,

\section{KARGER \\ Fax +4161306 1234 \\ E-Mail karger@karger.ch}

www.karger.com (c) 2008 S. Karger AG, Basel

$1464-1801 / 08 / 0151-0008 \$ 24.50 / 0$

Accessible online at:

www.karger.com $/ \mathrm{mmb}$
K.T. Shanmugam

Department of Microbiology and Cell Science

University of Florida

Gainesville, FL 32611 (USA)

Tel. +1 352392 2490, Fax +1 352392 5922, E-Mail shan@ufl.edu 
2004; Ragauskas et al., 2006; Singh et al., 2006; Wyman, 2003]. In addition, this review will be devoted to biocatalysts that are engineered to produce these products in contrast to the native organisms that produce these compounds since the metabolic requirements of an organism to produce a specific compound at high yield and purity can be better understood by following sequential improvement of the organism. This is not an exhaustive review of the literature and only selected literature is included to make the point.

LA is the simplest of the three compounds produced by the biocatalyst.

$$
\mathrm{C}_{6} \mathrm{H}_{12} \mathrm{O}_{6} \longrightarrow 2 \mathrm{C}_{3} \mathrm{H}_{6} \mathrm{O}_{3}
$$

In this conversion of glucose to LA, the redox state of carbon in LA is the same as that of the starting glucose $\left(\mathrm{CH}_{2} \mathrm{O}\right)$ although the glucose carbon undergoes oxidation/reduction during this transformation. On the other hand, the redox state of carbon in succinic acid is more oxidized than the glucose carbon and the excess reductant needs to be removed without interfering with the cellular metabolism. A stoichiometric reaction for glucose to succinic acid is listed below (reaction 2). Based on this reaction, every mole of succinate produced from glucose is equaled with a mole of acetate and the excess reductant $(2[\mathrm{H}])$ can be released as $\mathrm{H}_{2}$ to balance the equation.

$$
\mathrm{C}_{6} \mathrm{H}_{12} \mathrm{O}_{6} \longrightarrow \mathrm{C}_{4} \mathrm{H}_{6} \mathrm{O}_{4}+\mathrm{C}_{2} \mathrm{H}_{4} \mathrm{O}_{2}+2[\mathrm{H}]
$$

Carbon in acetate is at the same redox state as that of glucose carbon. But the combined redox state of the carbon in all the products is more oxidized than the glucose carbon. A deceptively simple reaction can be written for fermentation of glucose to 2 acetates (reaction 3). The metabolic pathway that leads to the production of acetate includes various oxidation/reduction reactions that generate NADH and ATP during this transformation to support biosynthesis.

$$
\mathrm{C}_{6} \mathrm{H}_{12} \mathrm{O}_{6}+2 \mathrm{H}_{2} \mathrm{O} \longrightarrow 2 \mathrm{C}_{2} \mathrm{H}_{4} \mathrm{O}_{2}+2 \mathrm{CO}_{2}+8[\mathrm{H}]
$$

Overall, only LA, besides ethanol, due to its redox neutral state, is produced as the sole product of fermentation by naturally occurring organisms at high yields and amounts [Bothast and Schlicher, 2005; Hofvendahl and Hans-Hagerdal, 2000]. Microbial production of the other two products requires manipulation of metabolic pathways to balance the redox state of the overall pathway that is a combination of several individual reactions.

For a biocatalyst to be effective it must meet the following characteristics: (1) high specific productivity; (2) high growth rate and cell yield; (3) maintain the high specific productivity through the fermentation cycle; (4) tolerance to high concentrations of substrate sugars; (5) tolerance to high concentrations of product; (6) absence of contaminating co-products, and (7) ability to grow and ferment in mineral salts medium.

\section{Lactic Acid $\left(\mathrm{CH}_{3} \mathrm{CHOHCOOH} ; \mathrm{C}_{3} \mathrm{H}_{6} \mathrm{O}_{3}\right)$}

LA is produced from glucose by oxidizing NADH produced during glycolysis with pyruvate as the electron acceptor (fig. 1). Two lactate dehydrogenase (LDH) activities encoded by two separate genes each catalyzing the production of one or other enantioisomer (L+ or D-) has been detected in many of the LA bacteria (genome sequences at NCBI; http://www.ncbi.nlm.nih.gov/genomes/ lproks.cgi?view=1) [Hofvendahl and Hans-Hagerdal, 2000]. The level of optical purity of LA depends on the comparative level of expression of these two genes. Escherichia coli produces only the D-LDH catalyzing the production of D(-)-LA [Zhou et al., 2003a]. L(+)-LA-producing $E$. coli has been constructed by transferring the gene encoding L-LDH from other organisms (Pediococcus) into an $E$. coli that carries a deletion in the native $\operatorname{ldh} A$ gene [Zhou et al., 2003b].

LA bacteria also produce pyruvate formate-lyase (PFL) and the level of this enzyme activity depends on the nature and quantity of the carbon source in the medium [Garrigues et al., 1997; Melchiorsen et al., 2002]. Due to this presence of PFL, these cells produce small amounts of acetate and ethanol as potential impurities of LA. In an industrial scale fermentation that starts with a high concentration of sugar, such as glucose, the contribution of PFL to the overall fermentation balance is almost negligible.

For industrial production of LA, three issues need to be addressed: (1) high volumetric productivity and yield of a single optical isomer; (2) inhibition of growth and fermentation by LA, and (3) ability to ferment multiple sugar sources.

Although all LA bacteria ferment glucose and other hexoses, their ability to ferment pentoses (xylose, arabinose, etc.) is limited to few LA bacteria. Even these select LA bacteria utilize the phosphoketolase pathway that produces an equimolar mixture of LA and acetic acid making many of the LA bacteria unsuitable for pentose fermentation to LA [Garde et al., 2002; Patel et al., 2006; Tanaka et al., 2002]. E. coli derivatives have been engineered by several laboratories for production of optically 
Fig. 1. Fermentation pathways of lactic acid producers. 1 = Glucose transport; 2 = phosphohexose isomerase and phosphofructokinase; 3 = aldolase; 4 = glyceraldehyde-3-phosphate dehydrogenase; $5=$ phosphoglycerate kinase; $6=$ phosphoglyceromutase; 7 = enolase; $8=$ pyruvate kinase; 9 = lactate dehydrogenase; $10=$ pyruvate formate-lyase; 11 = phosphotransacetylase and acetate kinase; $12=$ alcohol dehydrogenase; 13 = methylglyoxal synthase; 14 = enzymes of the methyl glyoxal pathway to lactate; 15 = phosphotriose isomerase. DHAP = Dihydroxyacetone phosphate; GAP = glyceraldehyde-3-phosphate; $\mathrm{GA}=$ glyceric acid; PGA = phosphoglyceric acid; PEP = phosphoenolpyruvate.

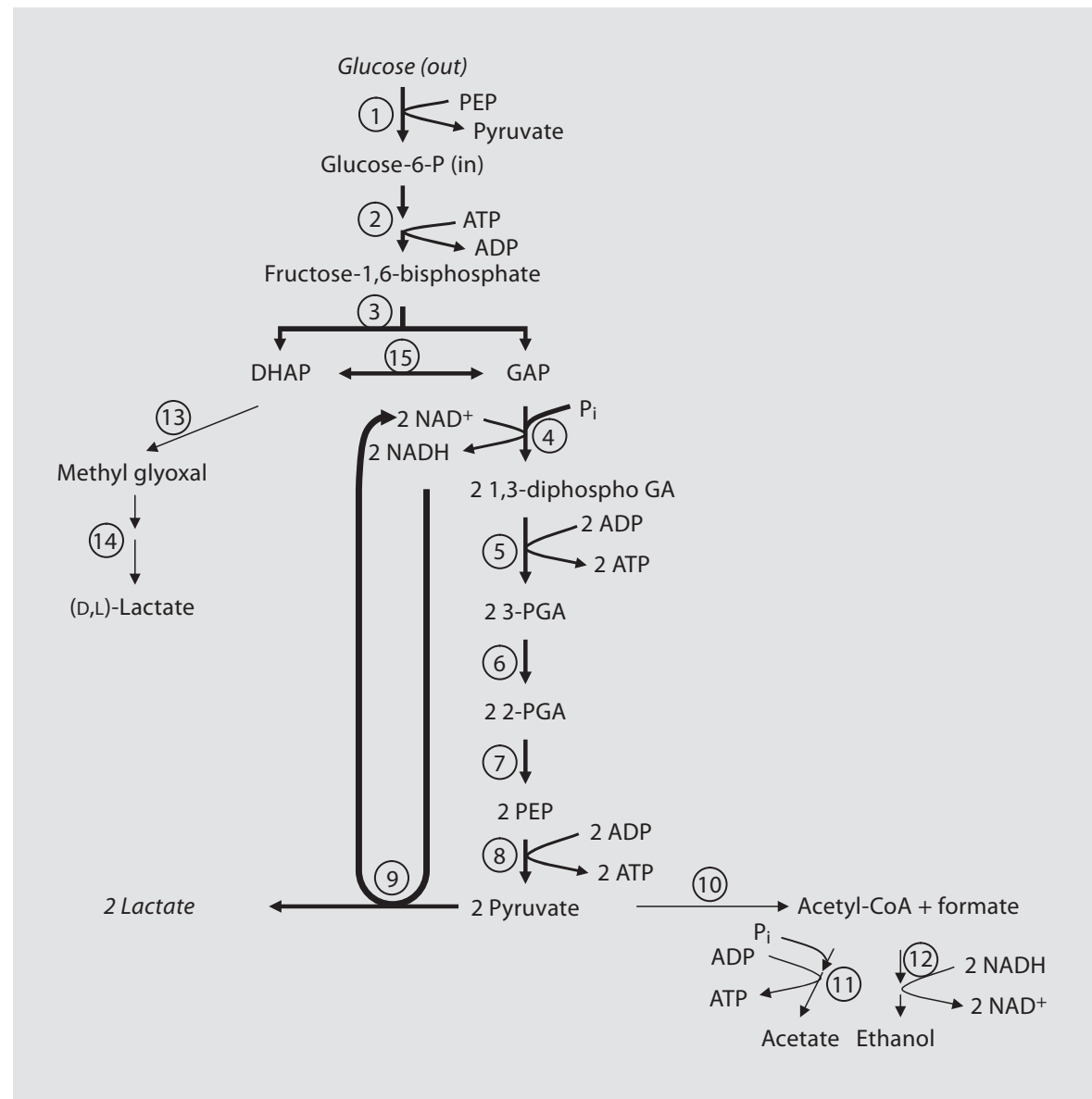

pure LA by deleting competing pathways [Chang et al., 1999; Dien et al., 2002; Grabar et al., 2006; Zhou et al., 2003a, b; Zhu and Shimizu, 2004]. These E. coli derivatives ferment all the sugars that can be derived from lignocellulosic biomass to products of choice.

Specific productivity of a biocatalyst depends on the flux of sugar carbon through the various enzymatic reactions to the product. Volumetric productivity is a combination of specific productivity and cell density. These two relationships dictate that it is important to maintain the biocatalyst at the highest specific productivity and at high cell density. Under these conditions, the highest rate of fermentation can be achieved even at high sugar concentrations with minimal osmotic effect since the rate of diffusion of sugar to the cell surface is countered by the rapid uptake and metabolism. One of the major challenges of fermentation is to generate a very high cell density culture in a short time and then maintain the high specific productivity of this culture during the non-growth phase. Building a high cell density culture requires higher growth
Table 1. Relationship between growth rate and volumetric productivity of $E$. coli strain SZ132

\begin{tabular}{llll}
\hline $\begin{array}{l}\text { Growth } \\
\text { medium }\end{array}$ & $\begin{array}{l}\text { Growth } \\
\text { rate } \mu, \mathrm{h}^{-1}\end{array}$ & $\begin{array}{l}\text { Specific produc- } \\
\text { tivity, mmol/g·h }\end{array}$ & $\begin{array}{l}\text { Volumetric produc- } \\
\text { tivity, mmol/l·h }\end{array}$ \\
\hline NBS & 0.14 & 26.6 & 8.6 \\
NBS + betaine & 0.23 & 36.0 & 24.5 \\
LB & 0.46 & 27.2 & 51.0 \\
\hline
\end{tabular}

Cultures were grown in the indicated medium with glucose $(100 \mathrm{~g} / \mathrm{l})$. Lactate was the main fermentation product. NBS = Mineral salt medium; LB = Luria Bertani medium. The betaine concentration was $1 \mathrm{mmol} / \mathrm{l}$ [Zhou et al., 2006].

rate and optimization of the growth medium to support this rate (table 1). This is more challenging in mineral salt medium and may require osmoprotectants [Zhou et al., 2006]. Since the growth rate is directly proportional to ATP yield per glucose due to a constant $\mathrm{Y}_{\text {ATP }}$ value, aerat- 
ing the culture during the growth phase followed by anaerobic fermentation has proved promising [Sanchez et al., 2005; Stouthamer, 1977; Tempest and Neijssel, 1984; Zhu and Shimizu, 2004]. In addition, there is a high rate of production of LA as the product diverts the carbon from biosynthetic needs to LA. Supplementation of the growth medium with the limiting nutrient (for example, acetate, glutamate, succinate, etc.) usually increases the volumetric productivity as demonstrated with ethanologenic E. coli [Underwood et al., 2002]. Replacing native citrate synthase with an enzyme from Bacillus subtilis that is insensitive to NADH partitioned enough carbon for biosynthesis. High sugar concentrations, especially in media that do not support high growth rates, also increases the osmotic stress on the organism that can be relieved by addition of osmoprotectants such as betaine to the medium (table 1). Relieving osmotic stress not only increased the growth rate but also increased specific productivity [Zhou et al., 2006]. As seen from the data in table 1, using cultures with the same specific productivity (mineral salt medium- vs. Luria Bertani-grown cells), the volumetric productivity can be substantially increased by increasing the growth rate and the resultant cell mass. Higher volumetric productivity translates to shorter fermentation time and improved economics of fermentation.

An alternate strategy to increase the growth rate of the biocatalyst under anaerobic growth conditions would be to increase the pyruvate flux through PFL, phosphotransacetylase and acetate kinase, reactions that increase the net ATP yield per glucose to three (fig. 1). However, this would contaminate the LA with acetate. The PFL is an essential component of ATP generation for growth in both $E$. coli and LA bacteria especially in media with limiting concentrations of sugars or in the presence of sugars that are consumed at a lower rate than glucose (such as galactose or pentoses) [Cselovszky et al., 1992; Hasona et al., 2004; Melchiorsen et al., 2001, 2002].

The rate of metabolic flux in a fermenting cell is always highest during the growth phase and immediately following this phase (fig. 2) [Zhou et al., 2003a]. Specific and volumetric productivities decrease as the biocatalyst ages. One of the causative agents for this decline is probably the high ATP/ADP ratio associated with a high metabolic flux and a low rate of biosynthesis. This ratio is maintained at a constant optimum level during growth since the production and consumption of ATP is always balanced [Chapman et al., 1971; Patnaik et al., 1992]. With a decline in ATP demand for biosynthesis during the post-growth phase, the cell attempts to maintain this ratio by decreasing the glucose flux that in turn reduces

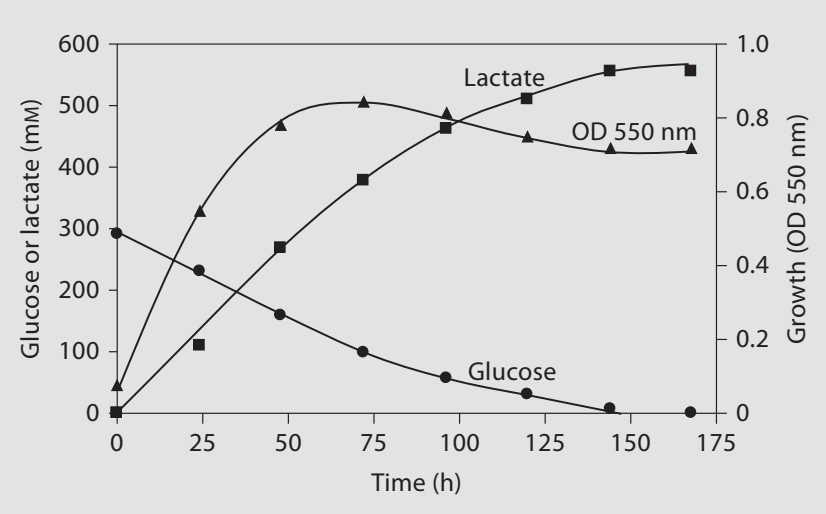

Fig. 2. Fermentation of glucose to lactic acid by E. coli strain SZ63.

the specific productivity. This has been addressed by reducing the ATP production or ATP recycling by non-productive reactions [Koebmann et al., 2002; Patnaik et al., 1992]. Release of ATPase from the membrane into the cytoplasm to increase ATP turnover has increased glucose flux. Arsenate, an analog of phosphate has been used to reduce net ATP yield during fermentation in permeabilized cells to increase glucose flux [Takeshige and Ouchi, 1995]. Arsenate substitutes for phosphate in the glyceraldehyde-3-phosphate dehydrogenase reaction and the unstable product, 1-arseno, 3-phosphoglycerate, spontaneously and rapidly hydrolyses to 3-phosphoglycerate without ATP production that is associated with the native reaction.

These studies show that the ATP/ADP ratio in the fermenting cell needs to be maintained at levels that are comparable to that of an actively growing cell to support the high flux rate. A higher ATP/ADP ratio tends to decrease the glycolytic flux while a ratio that is too low evokes alternate pathways that yield ATP.

LA at high concentrations and low $\mathrm{pH}$ also inhibits growth of the organism, although the level of inhibition varies according to the organism [Pieterse et al., 2005]. Although the mechanism of this inhibition is unclear, it is believed that it is linked to the amount of the protonated form of LA that can traverse the cell membrane. Higher LA accumulation is believed to disrupt membrane potential leading to growth and fermentation arrest. Variants can be obtained by directed evolution of the biocatalyst that tolerates high acids during fermentation [Grabar et al., 2006]. Genetic and metabolic analysis of these derivatives is expected to provide clues towards fur- 
Fig. 3. Pathways of fermentation of glucose to succinic acid in E. coli. 1 = Glycolysis pathway; 2 = PEP carboxylase; 3 = malate dehydrogenase; 4 = fumarase; 5 = fumarate reductase; $6=$ hydrogen uptake system; 7 = pyruvate kinase; 8 = pyruvate dehydrogenase; $9=$ citrate synthase; $10=$ aconitase; 11 = isocitrate lyase; $12=$ malate synthase. $\mathrm{PEP}=$ Phosphoenolpyruvate; $\mathrm{OAA}=$ oxaloacetic acid.

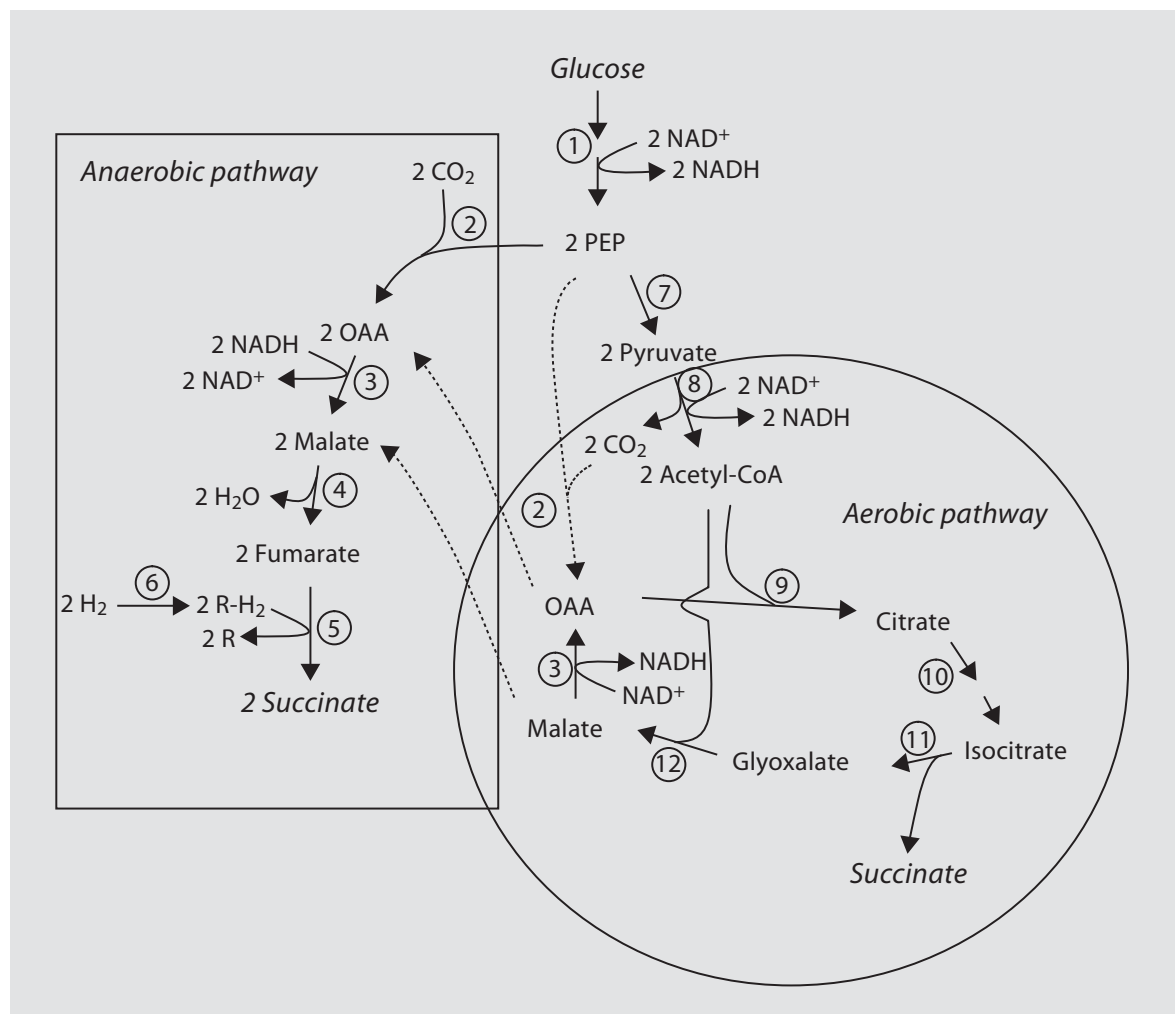

ther metabolic engineering of biocatalysts that can produce still higher concentrations of acidic products.

Adaptation of these basic principles led to development of $E$. coli derivatives by metabolic engineering and directed evolution that produce as high as $1.3 \mathrm{M} \mathrm{L}(+)$ - or $\mathrm{D}(-)-\mathrm{LA}(117 \mathrm{~g} / \mathrm{l})$ in $48 \mathrm{~h}$ with a yield of $98 \%$ and chiral purity of $99.9 \%$ in a simple mineral salt medium [Grabar et al., 2006].

\section{Succinic Acid $\left(\mathrm{HOOCCH}_{2} \mathrm{CH}_{2} \mathrm{COOH} ; \mathrm{C}_{4} \mathrm{H}_{6} \mathrm{O}_{4}\right)$}

Production of succinic acid as the sole product from glucose is more challenging than LA and this has been addressed by several laboratories. At least three naturally occurring organisms, A. succinogenes, Anaerobiospirillum succiniproducens and Mannheima succiniproducens, produce succinate as a major fermentation product while also producing acetate, ethanol, formate and lactate as co-products at varying levels [Lee et al., 2002, 2003; McKinlay et al., 2005; Song and Lee, 2006]. These bacteria have been engineered to increase the yield and purity of succinic acid. M. succiniproducens mutant strains that lack $l d h, p f l, p t a$ and $a c k A$ produced succinate at a molar yield of 1.16 per glucose [Lee et al., 2006]. If all the carbon in glucose is converted to succinic acid, analogous to LA fermentation, the expected molar yield is 1.5 succinates per glucose. Since the pathway to succinate from sugars is through phosphoenolpyruvate (PEP), a 3-carbon intermediate, $\mathrm{CO}_{2}$ fixation is an integral part of succinate production (fig. 3). With supplementation of fermentation with $\mathrm{CO}_{2}$ the molar yield of succinate increases to $1.7 \mathrm{per}$ glucose. A maximum yield of 2 succinates per glucose is not unrealistic provided additional required reductant can also be supplied.

The basic reaction would be,

$$
\mathrm{C}_{6} \mathrm{H}_{12} \mathrm{O}_{6}+2 \mathrm{CO}_{2}+2 \mathrm{H}_{2} \longrightarrow 2 \mathrm{C}_{4} \mathrm{H}_{6} \mathrm{O}_{4}+2 \mathrm{H}_{2} \mathrm{O}
$$

A net yield of 2 succinates per glucose would require appropriate engineering of the biocatalyst and inclusion of $\mathrm{H}_{2}$ and $\mathrm{CO}_{2}$ in the fermentation. In this section, we will attempt to outline the critical factors that need to be addressed in such a metabolic engineering of a biocatalyst for succinate production. Again, we will use E. coli as the model system because of its metabolic versatility, genetic amenability, ease of use and successful metabolic engineering for ethanol and LA production. The pathways that lead to succinate production under aerobic and an- 
aerobic conditions are presented in figure 3. In an anaerobic cell, succinate pathway starts from PEP. A molecule of $\mathrm{CO}_{2}$ is fixed on PEP to produce oxaloacetic acid (OAA). By the reversal of the tricarboxylic acid cycle utilizing malate dehydrogenase and fumarase, fumarate is produced. Fumarate reductase (FR; menaquinol fumarate oxidoreductase), a membrane-bound flavoprotein catalyzes the reduction of fumarate to succinate and the specific nature of the reductant for FR in E. coli is not known and the enzyme FR failed to use $\mathrm{NADH}$ as the $[\mathrm{H}]$ donor. Anaerobic growth of E. coli with $\mathrm{H}_{2}$ as the electron donor and fumarate as the electron acceptor has been demonstrated, and either formate or $\mathrm{H}_{2}$ can serve as the native electron donor for succinate production in this bacterium [Bernhard and Gottschalk, 1978]. In support of this, mutant strains that are defective in formate hydrogen-lyase produced significantly lower levels of succinate [Alam and Clark, 1989]. In addition, supplementation of A. succiniproducens fermentation with $\mathrm{H}_{2}$ almost doubled the volumetric productivity of succinate from glucose [Lee et al., 1999].

As presented in figure 3, anaerobic succinate production requires two pairs of reductants in contrast to LA that requires only one NADH per lactate produced. Since glycolytic production of PEP generates only one NADH per PEP, due to redox constraints, succinate is not a major component of $E$. coli fermentation [Clark, 1989]. In addition, PEP is the source of energy for glucose transport and phosphate for glucose-6-phosphate. The PEP requirement has been addressed by either introducing a PEP-independent sugar transport system (such as altered galactose transport that transports glucose) [Hernandez-Montalvo et al., 2003] or a heterologous pyruvate carboxylase to produces oxaloacetate [Sanchez et al., 2005]. In addition, if the glucose carbon is diverted to succinate at the pyruvate level, $\mathrm{CO}_{2}$ needs to be supplied externally.

$E$. coli has been engineered to produce succinate both under aerobic and anaerobic conditions [Lin et al., 2005; Sanchez et al., 2005]. The reported succinate yield under anaerobic conditions was slightly higher than 1.0. When engineered E. coli that lacks 2-oxoglutarate dehydrogenase (suc) and also carries mutations altering the regulation of isocitrate dehydrogenase was grown under aerobic conditions, the glyoxalate pathway dominated succinate production with a molar yield of 1.0 succinate per glucose (fig. 3). Citrate synthase, aconitase, isocitrate lyase, malate synthase and malate dehydrogenase function in a cyclic manner converting two acetyl-CoA to one succinate. Since succinate production under aerobic conditions is a non-reductive process, the NADH generated during this process can be oxidized by the respiratory electron transport chain but the associated increase in ATP yield, as discussed above, needs to be addressed.

Sanchez et al. [2005] further engineered mutant derivatives of $E$. coli that apparently combined fumarase and FR of the anaerobic pathway with the glyoxylate pathway that produced about 1.7 succinates per glucose under anaerobic conditions with $\mathrm{CO}_{2}$ supplementation. The stoichiometry for this reaction is as follows:

$$
\mathrm{C}_{6} \mathrm{H}_{12} \mathrm{O}_{6}+\mathrm{CO}_{2} \longrightarrow 1.7 \mathrm{C}_{4} \mathrm{H}_{6} \mathrm{O}_{4}+\mathrm{H}_{2} \mathrm{O}
$$

Apparently, a fine balance exists in this construct between the operation of the glyoxalate pathway and the reductive production of succinate that also maintains the redox balance. These and other studies show that the critical component that increases succinate yield is an increase in OAA pool size.

An engineered $E$. coli that produces a heterologous pyruvate carboxylase that spares PEP for glucose transport is expected to increase the OAA pool in a medium supplemented with $\mathrm{CO}_{2}$. The $2 \mathrm{NADHs}$ produced during the production of 2 pyruvates can be used to reduce the 2 OAA to 2 malates. Further reduction of fumarate to succinate would require an external supply of reductant such as $\mathrm{H}_{2}$. Appropriate engineering of the $\mathrm{H}_{2}$ uptake system to express the enzyme complex even in the presence of high sugar would be an additional requirement to increase the succinate yield to 2 per glucose.

\section{Acetic Acid $\left(\mathrm{CH}_{3} \mathrm{COOH} ; \mathrm{C}_{2} \mathrm{H}_{4} \mathrm{O}_{2}\right)$}

Although acetic acid carbon has the same redox state of the starting glucose carbon, $\mathrm{CO}_{2}$ released during acetate production changes the combined redox state of the carbon in the reaction products (reaction 3 ) to be more oxidized and the reductants generated during acetate $\left(+\mathrm{CO}_{2}\right)$ production need to be removed by alternate means because the normal pathways for NADH oxidation through reduction of pyruvate (to lactate) or acetylCoA (to ethanol) is no longer available (fig. 1).

$$
\text { Sum: } \frac{2 \mathrm{CO}_{2}+8[\mathrm{H}] \longrightarrow \mathrm{C}_{6} \mathrm{H}_{12} \mathrm{O}_{6}+2 \mathrm{H}_{2} \mathrm{O} \longrightarrow \mathrm{C}_{2} \mathrm{H}_{4} \mathrm{O}_{2}+2 \mathrm{CO}_{2}+8[\mathrm{H}]}{\mathrm{C}_{6} \mathrm{H}_{12} \mathrm{O}_{6} \longrightarrow \mathrm{C}_{4} \mathrm{O}_{2}+2 \mathrm{H}_{2} \mathrm{O}}
$$

Naturally occurring homoacetate producers such as Moorella thermoacetica (formerly Clostridium thermoaceticum), C. formicoaceticum and several other clostridia can utilize formate or $\mathrm{CO}_{2}$ as the electron acceptor that leads to production of an additional acetate with a 
yield of 3 acetates per hexose (reactions 6 and 7) [Drake and Daniel, 2004; Huang et al., 1998; Tammali et al., 2003]. The acetate yield in batch fermentation by C. formicoaceticum is about $0.91 \mathrm{~g} / \mathrm{g}$ fructose but the volumetric productivity is low $(0.19 \mathrm{~g} / \mathrm{l} \cdot \mathrm{h})$ [Huang et al., 1998]. However, the inability of this acetogen to ferment glucose limits its utility as a biocatalyst. Cocultures of two or more organisms have been constructed to increase the substrate range of this acetogen. In these cocultures, one organism produced LA from sugars that was converted to acetate by Moorella or Clostridia [Collet et al., 2003; Talabardon et al., 2000]. In an industrial scale production of acetic acid, stable consortia are difficult to achieve and maintain due to the specific physiological requirements of each of the members.

Although the yield of acetate from an engineered $E$. coli is only about 2.0 per glucose (reaction 3 ), this bacterium has a record of industrial use. In such an engineered acetogenic E. coli, the NADH is reoxidized through the electron transport chain by $\mathrm{O}_{2}$. Introducing $\mathrm{O}_{2}$ into the fermentation caused two unexpected problems, continued growth of the biocatalyst that diverts sugar to cell mass and an increase in ATP yield. Since a high ATP/ $\mathrm{ADP}$ ratio limits the carbon flux, an effective means of reducing the ATP/ADP ratio is a prerequisite for high acetate yield. This was addressed by releasing the ATP synthase from the membrane to prevent $\mathrm{H}^{+}$-coupled ATP production [Causey et al., 2003]. The presence of ATPase in the cytoplasm is expected to increase ATP hydrolysis that would also decrease the ATP/ADP ratio. By combining various mutations that eliminated alternate pathways and by appropriate ATP synthase mutation, Causey et al. [2003] engineered E. coli (strain TC36) to produce acetate as the sole product under aerobic conditions with a highest yield of $86 \%$ of the expected maximum from glucose. The total amount of acetate produced by strain TC36 with a specific productivity of $1 \mathrm{~g} / \mathrm{h} \cdot(\mathrm{g}$ cell mass) was about $53 \mathrm{~g} / \mathrm{l}$. This was achieved in a fed-batch under $5 \%$ dissolved $\mathrm{O}_{2}$. Volumetric productivity of strain TC36 was about $1.4 \mathrm{~g} / \mathrm{l} \cdot \mathrm{h}$, a value that is about 7 times higher than the reported values for naturally occurring acetogens [Causey et al., 2003; Huang et al., 1998].

By engineering a pathway into $E$. coli that would reoxidize NADH to $\mathrm{H}_{2}$, acetate production can be accomplished in an anaerobic atmosphere, a preferred condition for industrial production of commodity chemicals. There are several NADH-dependent $\mathrm{H}_{2}$ production pathways in nature and these are the next steps in engineering E. coli for production of either oxidized or reduced compounds of choice.

\section{Acknowledgements}

This work was supported by grants from the US Department of Energy (FG02-96ER20222 and FG36-04GO14019), Bioenergy International, LLC and Florida Agricultural Experiment Station.

\section{References}

-Alam KY, Clark DP: Anaerobic fermentation balance of Escherichia coli as observed by in vivo nuclear magnetic resonance spectroscopy. J Bacteriol 1989;171:6213-6217.

- Bernhard TH, Gottschalk G: Cell yields of Escherichia coli during anaerobic growth on fumarate and molecular hydrogen. Arch Microbiol 1978;116:235-238.

Bothast RJ, Schlicher MA: Biotechnological processes for conversion of corn into ethanol. Appl Microbiol Biotechnol 2005;67:19-25.

-Causey TB, Zhou S, Shanmugam KT, Ingram LO: Engineering the metabolism of Escherichia coli W3110 for the conversion of sugar to redox-neutral and oxidized products: homoacetate production. Proc Natl Acad Sci USA 2003; 100:825-832.

-Chang DE, Jung HC, Rhee JS, Pan JG: Homofermentative production of D- or L-lactate in metabolically engineered Escherichia coli RR1. Appl Environ Microbiol 1999;65:13841389.
Chapman AG, Fall L, Atkinson DE: Adenylate energy charge in Escherichia coli during growth and starvation. J Bacteriol 1971;108: 1072-1086.

Clark DP: The fermentation pathways of Escherichia coli. FEMS Microbiol Rev 1989;5:223234.

Collet C, Schwitzguebel JP, Peringer P: Improvement of acetate production from lactose by growing Clostridium thermolacticum in mixed batch culture. J Appl Microbiol 2003; 95:824-831.

Cselovszky J, Wolf G, Hammes WP: Production of formate, acetate, and succinate by anaerobic fermentation of Lactobacillus pentosus in the presence of citrate. Appl Microbiol Biotechnol 1992;37:94-97.

Datta R, Henry M: Lactic acid: recent advances in products, processes and technologies - a review. J Chem Technol Biotechnol 2006;81: 1119-1129.
Dien BS, Nichols NN, Bothast RJ: Fermentation of sugar mixtures using Escherichia coli catabolite repression mutants engineered for production of L-lactic acid. J Ind Microbiol Biotechnol 2002;29:221-227.

Drake HL, Daniel SL: Physiology of the thermophilic acetogen Moorella thermoacetica. Res Microbiol 2004;155:869-883.

Dukes JS: Burning buried sunshine: human consumption of ancient solar energy. Climatic Change 2003;61:31-44.

Garde A, Jonsson G, Schmidt AS, Ahring BK: Lactic acid production from wheat straw hemicellulose hydrolysate by Lactobacillus pentosus and Lactobacillus brevis. Bioresour Technol 2002;81:217-223.

Garrigues C, Loubiere P, Lindley ND, CocaignBousquet M: Control of the shift from homolactic acid to mixed-acid fermentation in Lactococcus lactis: predominant role of the $\mathrm{NADH} / \mathrm{NAD}^{+}$ratio. J Bacteriol 1997;179: 5282-5287. 
- Grabar TB, Zhou S, Shanmugam KT, Yomano LP, Ingram LO: Methylglyoxal bypass identified as source of chiral contamination in $\mathrm{L}(+)$ and $\mathrm{D}(-)$-lactate fermentations by recombinant Escherichia coli. Biotechnol Lett 2006;28:1527-1535.

-Hahn-Hagerdal B, Galbe M, Gorwa-Grauslund MF, Liden G, Zacchi G: Bio-ethanol - the fuel of tomorrow from the residues of today. Trends Biotechnol 2006;24:549-556.

-Hasona A, Kim Y, Healy FG, Ingram LO, Shanmugam KT: Pyruvate formate lyase and acetate kinase are essential for anaerobic growth of Escherichia coli on xylose. J Bacteriol 2004;186:7593-7600.

-Hernandez-Montalvo V, Martinez A, Hernandez-Chavez G, Bolivar F, Valle F, Gosset G: Expression of galP and glk in a Escherichia coli PTS mutant restores glucose transport and increases glycolytic flux to fermentation products. Biotechnol Bioeng 2003;83:687694.

-Hofvendahl K, Hans-Hagerdal B: Factors affecting the fermentative lactic acid production from renewable resources. Enzyme Microb Technol 2000;26:87-107.

-Huang YL, Mann K, Novak JM, Yang ST: Acetic acid production from fructose by Clostridium formicoaceticum immobilized in a fibrous-bed bioreactor. Biotechnol Prog 1998; 14:800-806.

-Jones DT, Woods DR: Acetone-butanol fermentation revisited. Microbiol Rev 1986;50:484524.

Kheshgi HS, Prince RC, Marland G: The potential of biomass fuels in the context of global climate change: focus on transportation fuels. Annu Rev Energy Environ 2000;25:199244.

Koebmann BJ, Westerhoff HV, Snoep JL, Nilsson D, Jensen PR: The glycolytic flux in Escherichia coli is controlled by the demand for ATP. J Bacteriol 2002;184:3909-3916.

- Lee PC, Lee SY, Hong SH, Chang HN: Isolation and characterization of a new succinic acidproducing bacterium, Mannheima succiniproducens MBEL55E, from bovine rumen. Appl Microbiol Biotechnol 2002;58:663668.

Lee PC, Lee SY, Hong SH, Chang HN, Park SC: Biological conversion of wood hydrolysate to succinic acid by Anaerobiospirillum succiniciproducens. Biotechnol Lett 2003;25: 111-114.

- Lee PC, Lee WG, Kwon S, Lee SY, Chang HN: Succinic acid production by Anaerobiospirillum succiniciproducens: effects of the $\mathrm{H}_{2} \mathrm{CO}_{2}$ supply and glucose concentration. Enzyme Microb Technol 1999;24:549-554.

Lee SJ, Song H, Lee SY: Genome-based metabolic engineering of Mannheimia succiniciproducens for succinic acid production. Appl Environ Microbiol 2006;72:1939-1948.
Lin H, Bennett GN, San KY: Fed-batch culture of a metabolically engineered Escherichia coli strain designed for high-level succinate production and yield under aerobic conditions. Biotechnol Bioeng 2005;90:775-779.

Lynd LR, van Zyl WH, McBride JE, Laser M: Consolidated bioprocessing of cellulosic biomass: an update. Curr Opin Biotechnol 2005; 16:577-583.

McKinlay JB, Zeikus JG, Vieille C: Insights into Actinobacillus succinogenes fermentative metabolism in a chemically defined growth medium. Appl Environ Microbiol 2005;71: 6651-6656.

Melchiorsen CR, Jensen NB, Christensen B, Vaever Jokumsen K, Villadsen J: Dynamics of pyruvate metabolism in Lactococcus lactis. Biotechnol Bioeng 2001;74:271-279.

-Melchiorsen CR, Jokumsen KV, Villadsen J, Israelsen $\mathrm{H}$, Arnau J: The level of pyruvate-formate lyase controls the shift from homolactic to mixed-acid product formation in Lactococcus lactis. Appl Microbiol Biotechnol 2002;58:338-344.

-Narayanan N, Roychoudhury PK, Srivastava A: $\mathrm{L}(+)$ lactic acid fermentation and its product polymerization. Electronic J Biotechnol 2004;7:167-179.

Patel MA, Ou MS, Harbrucker R, Aldrich HC, Buszko ML, Ingram LO, Shanmugam KT: Isolation and characterization of acid-tolerant, thermophilic bacteria for effective fermentation of biomass-derived sugars to lactic acid. Appl Environ Microbiol 2006;72: 3228-3235.

Patnaik R, Roof WD, Young RF, Liao JC: Stimulation of glucose catabolism in Escherichia coli by a potential futile cycle. J Bacteriol 1992;174:7527-7532.

Pieterse B, Leer RJ, Schuren FH, van der Werf MJ: Unravelling the multiple effects of lactic acid stress on Lactobacillus plantarum by transcription profiling. Microbiology 2005; 151:3881-3894.

Ragauskas AJ, Williams CK, Davison BH, Britovsek G, Cairney J, Eckert CA, Frederick WJ, Jr., Hallett JP, Leak DJ, Liotta CL, Mielenz JR, Murphy R, Templer R, Tschaplinski T: The path forward for biofuels and biomaterials. Science 2006;311:484-489.

Sanchez AM, Bennett GN, San KY: Novel pathway engineering design of the anaerobic central metabolic pathway in Escherichia coli to increase succinate yield and productivity. Metab Eng 2005;7:229-239.

Singh SK, Ahmed SU, Pandey A: Metabolic engineering approaches for lactic acid production. Process Biochem 2006;41:991-1000.
Song H, Lee SY: production of succinic acid by bacterial fermentation. Enzyme Microb Technol 2006;39:352-361.

-Stouthamer AH: Energetic aspects of the growth of micro-organisms. Symp Soc Gen Microbiol 1977;27:285-315.

Takeshige K, Ouchi K: Reconstruction of ethanol fermentation in permeabilized cells of the yeast Saccharomyces cerevisiae. J Ferm Bioeng 1995;79:11-16.

Talabardon M, Schwitzguebel JP, Peringer P, Yang ST: Acetic acid production from lactose by an anaerobic thermophilic coculture immobilized in a fibrous-bed bioreactor. Biotechnol Prog 2000;16:1008-1017.

Tammali R, Seenayya G, Reddy G: Fermentation of cellulose to acetic acid by Clostridium lentocellum SG6: induction of sporulation and effect of buffering agent on acetic acid production. Lett Appl Microbiol 2003;37:304308.

Tanaka K, Komiyama A, Sonomoto K, Ishizaki A, Hall SJ, Stanbury PE: Two different pathways for D-xylose metabolism and the effect of xylose concentration on the yield coefficient of L-lactate in mixed-acid fermentation by the lactic acid bacterium Lactococcus lactis IO-1. Appl Microbiol Biotechnol 2002;60: 160-167.

Tempest DW, Neijssel OM: The status of $\mathrm{Y}_{\mathrm{ATP}}$ and maintenance energy as biologically interpretable phenomena. Annu Rev Microbiol 1984;38:459-486.

Underwood SA, Buszko ML, Shanmugam KT, Ingram LO: Flux through citrate synthase limits the growth of ethanologenic Escherichia coli KO11 during xylose fermentation. Appl Environ Microbiol 2002;68:1071-1081.

-Wyman CE: Potential synergies and challenges in refining cellulosic biomass to fuels, chemicals, and power. Biotechnol Prog 2003;19: 254-262.

Zhou S, Causey TB, Hasona A, Shanmugam KT, Ingram LO: Production of optically pure $\mathrm{D}$ lactic acid in mineral salts medium by metabolically engineered Escherichia coli W3110. Appl Environ Microbiol 2003a;69:399-407.

Zhou S, Grabar TB, Shanmugam KT, Ingram LO: Betaine tripled the volumetric productivity of D(-)-lactate by Escherichia coli strain SZ132 in mineral salts medium. Biotechnol Lett 2006;28:671-676.

Zhou S, Shanmugam KT, Ingram LO: Functional replacement of the Escherichia coli D-(-)lactate dehydrogenase gene $(l d h A)$ with the L-(+)-lactate dehydrogenase gene (ldhL) from Pediococcus acidilactici. Appl Environ Microbiol 2003b;69:2237-2244.

Zhu J, Shimizu K: The effect of $p f l$ gene knockout on the metabolism for optically pure D-lactate production by Escherichia coli. Appl Microbiol Biotechnol 2004;64:367-375. 